\title{
Inter-phylum negative interactions affect soil bacterial community dynamics and functions during soybean development under long-term nitrogen fertilization
}

\author{
Chunfang Zhang, Shuo Jiao, Duntao Shu* and Gehong Wei ${ }^{*}$ (B)
}

\begin{abstract}
Understanding interspecies interactions is essential to predict the response of microbial communities to exogenous perturbation. Herein, rhizospheric and bulk soils were collected from five developmental stages of soybean, which grew in soils receiving 16-year nitrogen inputs. Bacterial communities and functional profiles were examined using high-throughput sequencing and quantitative PCR, respectively. The objective of this study was to identify the key bacterial interactions that influenced community dynamics and functions. We found that the stages of soybean development outcompeted nitrogen fertilization management in shaping bacterial community structure, while fertilization treatments significantly shaped the abundance distribution of nitrogen functional genes. Temporal variations in bacterial abundances increased in bulk soils, especially at the stage of soybean branching, which helps to infer underlying negative interspecies interactions. Members of Cyanobacteria and Actinobacteria actively engaged in inter-phylum negative interactions in bulk soils and soybean rhizosphere, respectively. Furthermore, the negative interactions between nitrogen-fixing functional groups and the reduction of nifH gene abundance were coupled during soybean development, which may help to explain the linkages between population dynamics and functions. Overall, these findings highlight the importance of inter-phylum negative interactions in shaping the correlation patterns of bacterial communities and in determining soil functional potential.
\end{abstract}

Keywords: Nitrogen management, Soybean development, Community spatiotemporal variations, Bacterial interactions, Functional groups, Nitrogen-cycling genes

\section{Introduction}

The soil microbiome plays an integral role in nutrient cycling and constitutes an important resource for sustainable agricultural production (van der Heijden et al. 2008). However, long-term chemical fertilizer application threatens soil biodiversity and agroecological services (Zhong et al. 2010). In contrast, livestock manure addition contributes to the restoration of soil bacterial diversity (Sun et al. 2015), and increases soil enzyme activity (Li

\footnotetext{
* Correspondence: donald.shu@nwafu.edu.cn; weigehong@nwsuaf.edu.cn State Key Laboratory of Crop Stress Biology for Arid Areas, Shaanxi Key Laboratory of Agricultural and Environmental Microbiology, College of Life Sciences, Northwest A\&F University, Yangling 712100, Shaanxi, China
}

et al. 2015). Long-term fertilization changes microbial composition and function, which could be further altered during soybean development. The rapid growth of soybean can not only improve the nutrient uptake by soybean roots, but also promote the secretion of roots (Leggett and Frere 1971; Tanaka et al. 2008). The root exudates of legume plants can serve as the energy sources of some soil microbes (Sugiyama and Yazaki 2012). The soybean rhizosphere selects a subset of bacterial communities from the bulk soil based on some specific functions related to nitrogen, phosphorus, potassium, and iron metabolism, which is beneficial to the growth and nutrition of soybean (Mendes et al. 2014). Moreover, the soybean-rhizobium 
symbiosis enhances soil fertility due to biological nitrogen fixation (Liebman et al. 2012). Soybean cultivation as green manure offers a promising approach to ameliorate the negative impact on soil nutrients caused by the longterm application of chemical nitrogen fertilizer. Therefore, exploring how soil bacterial communities and nitrogen functional traits respond to soybean cultivation after longterm nitrogen fertilization could help to guide agricultural management.

Both exogenous and endogenous factors shape microbial communities and their functions (Konopka et al. 2015; Zhang et al. 2021). On the one hand, agricultural management and plant selection interactively affect soil microbial communities and nitrogen cycling (Schmidt et al. 2019). On the other hand, it is widely recognized that microbial interactions play important roles in shaping community dynamics and functioning (Asiloglu et al. 2021; Konopka et al. 2015). A common environmental biotechnology is to stabilize microbial interactions by controlling microbial inoculums and environmental conditions in order to optimize metabolic processes (PerezGarcia et al. 2016). Therefore, the control of biological processes requires an understanding of microbial interactions (Zengler and Palsson 2012). Although the effects of plant and environmental factors on microbial communities have been well studied (Brown et al. 2020; Mendes et al. 2014), the consequences of bacterial interactions for communities and functions have not been fully understood.

Microorganisms exist in complex ecological webs. Microbial interactions within these ecological webs can have a positive impact, a negative impact or no impact on the species involved (Faust and Raes 2012). Cooccurrence model analysis indicates that interactions among root-associated fungal communities are predominantly positive (Abrego et al. 2020). Some studies have found that organic fertilizer amendment increases the ratio of bacteria to fungi, which is underpinned by the change of bacteria (Tao et al. 2015; Ye et al. 2021). Long-term manure application alters the composition of keystone taxa, and increases microbial network complexity (Ye et al. 2021). A previous study found that organic fertilizer reduced the population of pathogens, whilst antagonistic microbial groups negatively correlated with the pathogen populations (Tao et al. 2015). Furthermore, bacterial inoculants suppress pathogens, while increase the relative abundances of beneficial bacteria ( $\mathrm{Li}$ et al. 2021; Zhao et al. 2021). These findings highlight that negative interactions between soil microbes can lead to microbial abundance variations. Hence, we hypothesize that bacterial negative interactions play important roles in shaping dynamic variations in community composition under the legacy effects of long-term fertilization.
It is challenging to measure interspecies interactions in the whole microbial community through direct observation. Since interaction states might reach large numbers with only a few highly connected taxa, the key is to find the key interactions that have percolating effects at the community level (Grosskopf and Soyer 2014). Microbial networks can be used to predict interactions between species and to identify keystone taxa (Agler et al. 2016; Faust and Raes 2012). A previous study found that keystone taxa could explain community turnover better than all taxa combined (Herren and McMahon 2018), suggesting that they could be harnessed to predict shifts in microbial community composition (Banerjee et al. 2018). Exploring the co-occurrence patterns of keystone taxa would help to identify the key interactions in microbial communities (Huang et al. 2016; Liu et al. 2020).

Microbial community composition could affect ecosystem functioning. However, microbial communities similar in taxonomic composition could be dissimilar in functional potentials (Strickland et al. 2009). A previous study suggested that only a subset of microbes were vital for the mediation of biogeochemical cycles (Zhao et al. 2014). Microbial taxonomic composition and functional structure tend to be shaped by different processes (Louca et al. 2018). A global biogeographical study found that soil properties largely explained the variations in nitrogen-cycling traits, while weakly explaining the taxonomic composition of the corresponding functional groups (Nelson et al. 2016). Some studies observed that the relative abundances of specific bacterial phyla were useful parameters for predicting differences in soil functions in agricultural ecosystems (Nazaries et al. 2021; Zhong et al. 2020). The correlation between microbial taxonomic and functional composition is becoming the central question in microbial ecology. Understanding their associations can help to make decisions on how to regulate biological processes through the management of soil microbiota.

Identifying the mechanisms and consequences of microbial interactions will provide useful principles for developing predictive understandings of community dynamics and for the design of robust synthetic communities (Konopka et al. 2015). Nevertheless, how bacterial interaction patterns influence the soil microbiome remains unexplored during soybean development under long-term nitrogen addition. Therefore, the objectives of this study were (1) to reveal the spatiotemporal variation patterns of the overall bacterial community and nitrogen-cycling traits, (2) to predict the key interactions between keystone taxa and to verify their percolating effects at the overall community level, and (3) to explore to what extent bacterial interactions influence the nitrogen-cycling processes. 


\section{Results}

\section{Spatiotemporal variations of bacterial community and} nitrogen functional genes

Bacterial community differences were mainly driven by stage, and secondarily, by fertilization treatment. Soil compartment had a slight driving effect on the changes in community structure (Table 1 ). In view of the striking differences in bacterial community structure across different stages, the temporal effect was further analyzed using PCoA and PERMANOVA (Supplementary Fig. S2). Results showed that bacterial community structure became more similar between $\mathrm{CK}, \mathrm{N} 1$, and $\mathrm{N} 2$, as well as between $\mathrm{O} 1$ and $\mathrm{O} 2$ over time (Supplementary Table $\mathrm{S} 2$ ). However, bacterial community structure consistently differentiated between organic and mineral fertilization treatments. Moreover, the difference in community structure increased between bulk and rhizosphere samples as the development of soybean progressed (Supplementary Fig. S2).

The species that responded consistently to one treatment in six replicates could be clustered into three groups based on their abundance variation patterns (Fig. 1a, Supplementary Table S3). Operational taxonomic units (OTUs) within these three groups exhibited relatively uniform abundance distribution in rhizosphere samples across time scales. However, two groups of OTUs with high abundances showed opposite directions in abundance change across bulk samples at specific transition points (Fig. 1a), which suggested that some species were selected for while others were selected against at particular stages. In the rhizosphere, the periods when OTUs were specifically enriched or inhibited in large amounts were generally synchronous (Fig. 1b). In the bulk soil, around $60 \%$ of OTUs were specifically enriched at S2 and S3, and specifically inhibited at S3 and S4. Such specifically enriched OTUs were significantly more and less than specifically inhibited OTUs at S2 and S4, respectively (Fig. 1b, Supplementary Table S4). These results suggested that the asynchrony of

Table 1 Analysis of similarities (ANOSIM) and permutational multivariate analysis of variance (PERMANOVA)

\begin{tabular}{|c|c|c|c|c|c|}
\hline \multirow[t]{2}{*}{ Category $^{a}$} & \multirow[t]{2}{*}{ Group } & \multicolumn{2}{|c|}{ ANOSIM } & \multicolumn{2}{|c|}{ PERMANOVA } \\
\hline & & $\bar{R}$ & $P$ & $\overline{R^{2}}$ & $P$ \\
\hline \multirow[t]{3}{*}{ Bacteria } & Fertilization & 0.300 & $<0.001$ & 0.118 & $<0.001$ \\
\hline & Stage & 0.565 & $<0.001$ & 0.205 & $<0.001$ \\
\hline & Compartment & 0.157 & $<0.001$ & 0.038 & $<0.001$ \\
\hline \multirow[t]{3}{*}{ Genes } & Fertilization & 0.383 & $<0.001$ & 0.442 & $<0.001$ \\
\hline & Stage & 0.016 & 0.091 & 0.050 & $<0.001$ \\
\hline & Compartment & -0.003 & 0.534 & 0.003 & 0.005 \\
\hline
\end{tabular}

${ }^{a}$ The analysis is based on bacterial communities and the abundances of nitrogen functional genes enrichment and inhibition processes increased variation in bacterial community abundance.

The results of ANOSIM showed that the variation pattern of nitrogen functional genes was only determined by nitrogen fertilization management (Table 1). The driving effect of stages on variation in the abundance of functional genes could not be observed. Significance tests showed that all the analyzed genes significantly varied in abundance among different fertilization treatments. The genes involved in nitrogen fixation and anammox processes had higher abundances in $\mathrm{O} 1$ and $\mathrm{O} 2$ than in $\mathrm{N} 1$ and $\mathrm{N} 2$ treatments, with a fold change value of 2.6 for nifH gene and 2.4 for the 16S rRNA gene of anammox bacteria. However, the nrfA gene showed an opposite trend (Fig. 1c). In addition, five genes showed significant temporally-dependent abundance variation, including two in the nitrification process and three in the denitrification process. In particular, the abundances of the $A O B$ amo $A$ gene were significantly lower at S1 and S2 than at the later stages (Fig. 1d). Moreover, nirK and nos $Z$ genes had significantly higher abundances in rhizosphere than in bulk samples (Fig. 1e).

Interaction patterns of temporally specifically-selected taxa The observed networks of temporally specifically-selected sub-communities had higher average clustering coefficients, average path lengths, and modularity than the corresponding random networks (Supplementary Table S5). Keystone taxa were identified in the specifically selected sub-communities. The keystone members of Cyanobacteria negatively correlated with the keystone members of Proteobacteria, Actinobacteria and other keystone phyla in bulk samples, except for O2 treatment (Fig. 2). In contrast, the interactions among keystone Cyanobacteria were positive in bulk samples. However, the role of Cyanobacteria as keystone taxa was not detected in the rhizosphere samples. Most of these cyanobacterial taxa belonged to unclassified genera. With regard to the network interactions between keystone taxa in rhizosphere samples, Burkholderia sp. and Beggiatoa (members of Proteobacteria) were actively involved in the intra-phylum negative interactions in $\mathrm{O} 1$ and $\mathrm{O} 2$ treatments, respectively (Fig. 2).

Figure 3 showed that the interaction patterns of keystone taxa applied to the temporally specifically-selected subcommunities. For instance, Cyanobacteria actively engaged in the inter-phylum negative interactions among the specifically selected sub-communities in bulk samples, particularly under low organic nitrogen treatment. However, the proportions of negative interactions involved with Cyanobacteria decreased, while the contribution of Actinobacteria to negative interactions increased, under inorganic nitrogen treatments in bulk samples. In addition, Proteobacteria, Acidobacteria, and Actinobacteria tended to engage in inter- and intra-phylum negative interactions among the specifically selected subcommunities, especially in rhizosphere samples (Fig. 3). 

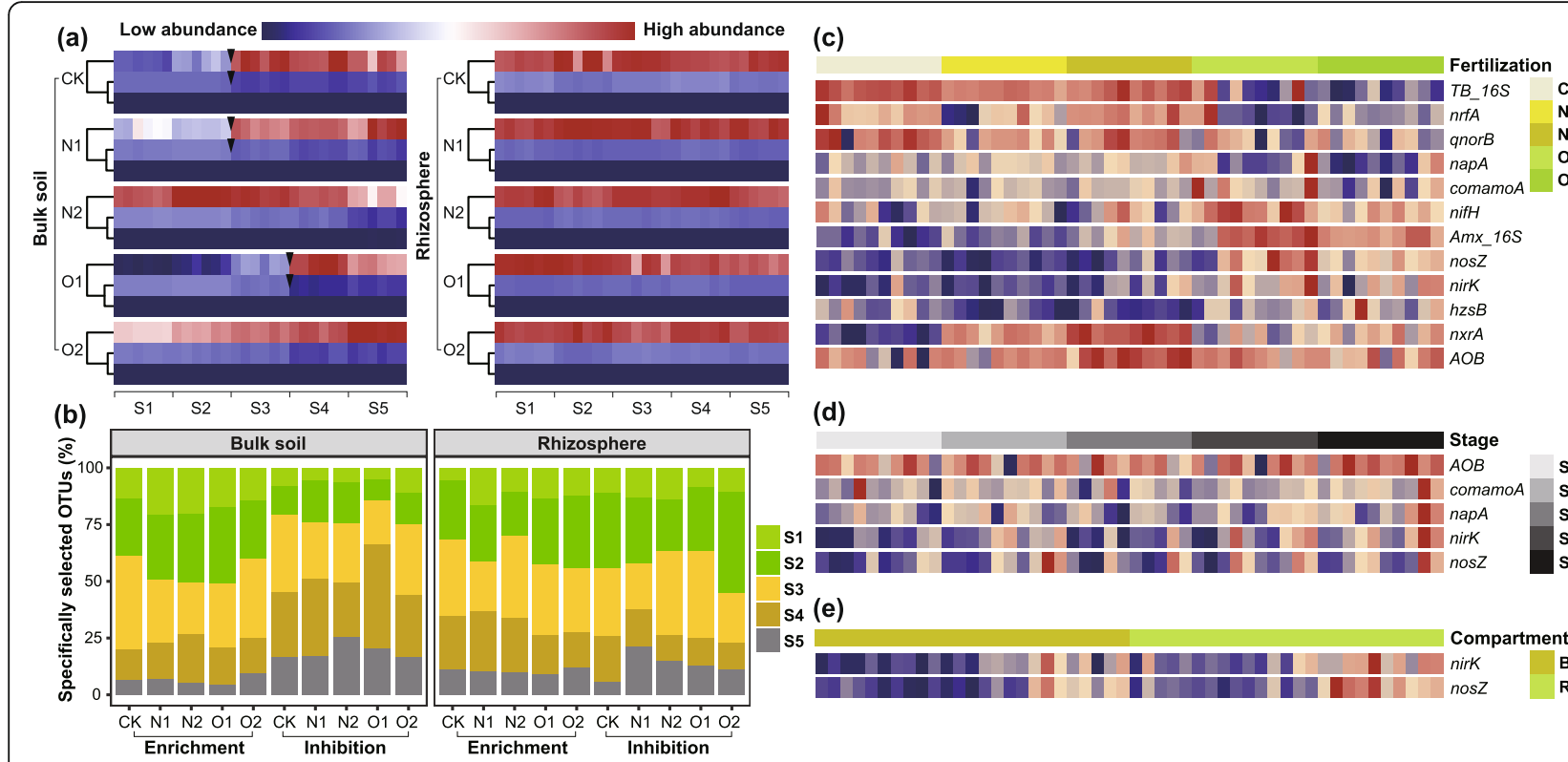

(d)

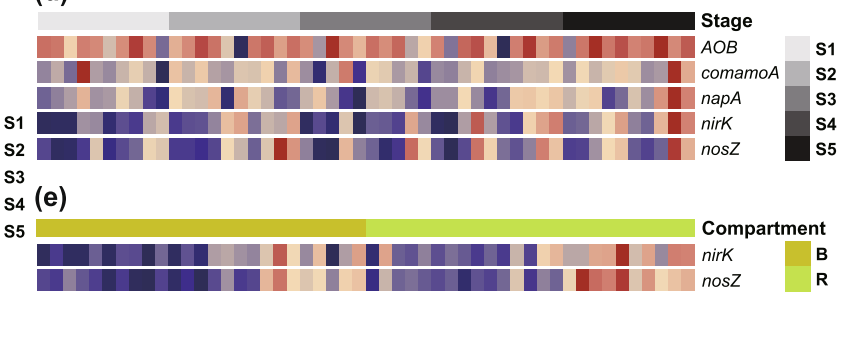

Fig. 1 Spatiotemporal distribution of bacterial communities and nitrogen functional genes. a Abundance variation patterns of OTUs on time scales. Each stage includes six replicates. OTUs are aggregated with three kmeans clusters in each treatment. b Proportions of the OTUs that have the highest or lowest relative abundances across all stages. c-e Average abundances of significantly-differentiated functional genes between different sample groups. Each average gene abundance is calculated from three replicates for each sample. The heatmap legend of Fig. 1c-e is shown in Fig. 1a. TB_16S, 16S rRNA genes of total bacteria; Amx_16S, 16S rRNA genes of anammox bacteria; $A O B, A O B$ amoA; comamoA, comammox clade A; CK, no fertilizer; N1, low urea input; N2, high urea input; $O 1$, low sheep manure input; O2, high sheep manure input. B, bulk soil; R, rhizosphere; S1, S2, S3, S4, and S5 represent one, three, five, seven, and nine weeks post transplantation, respectively

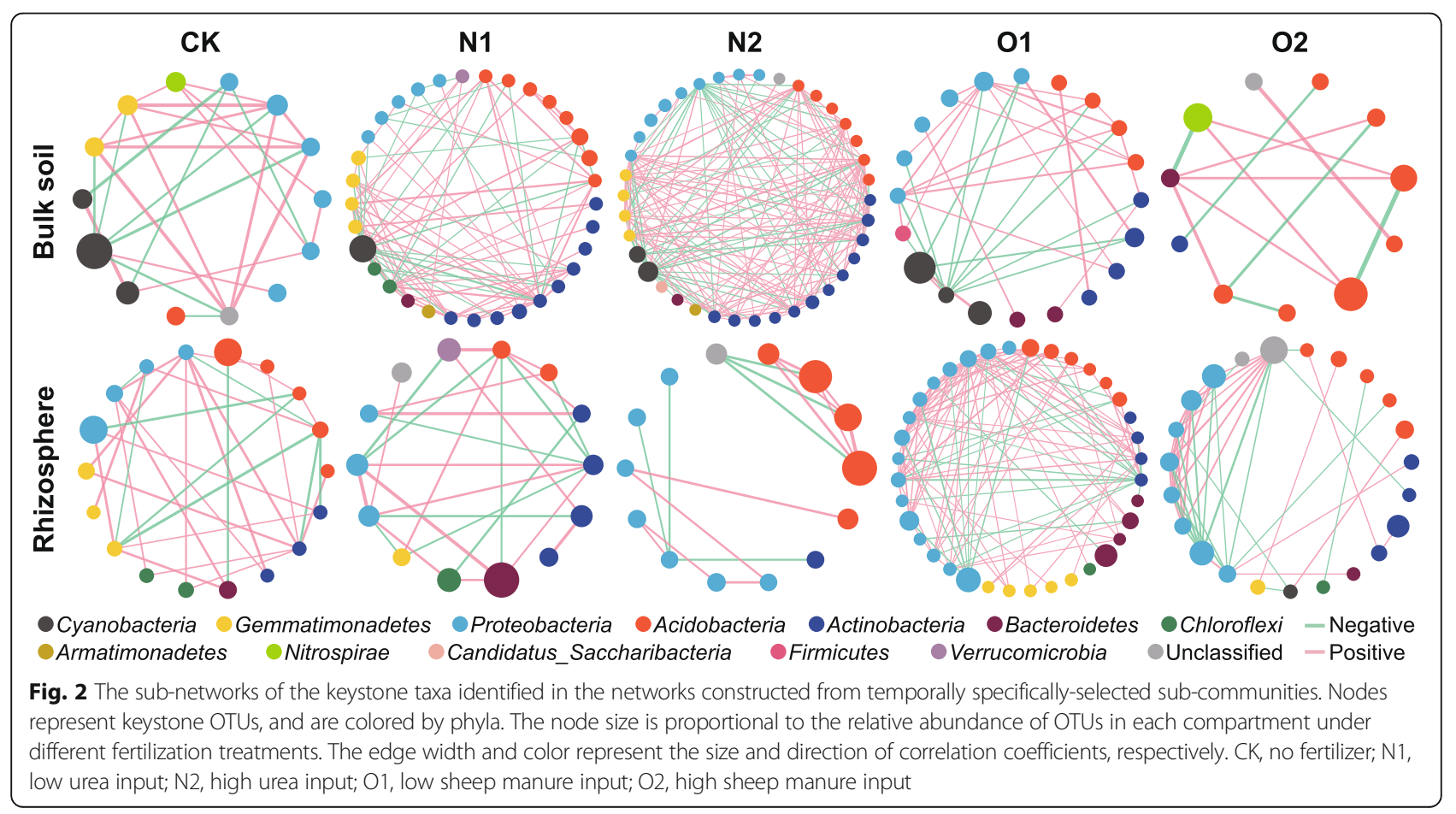




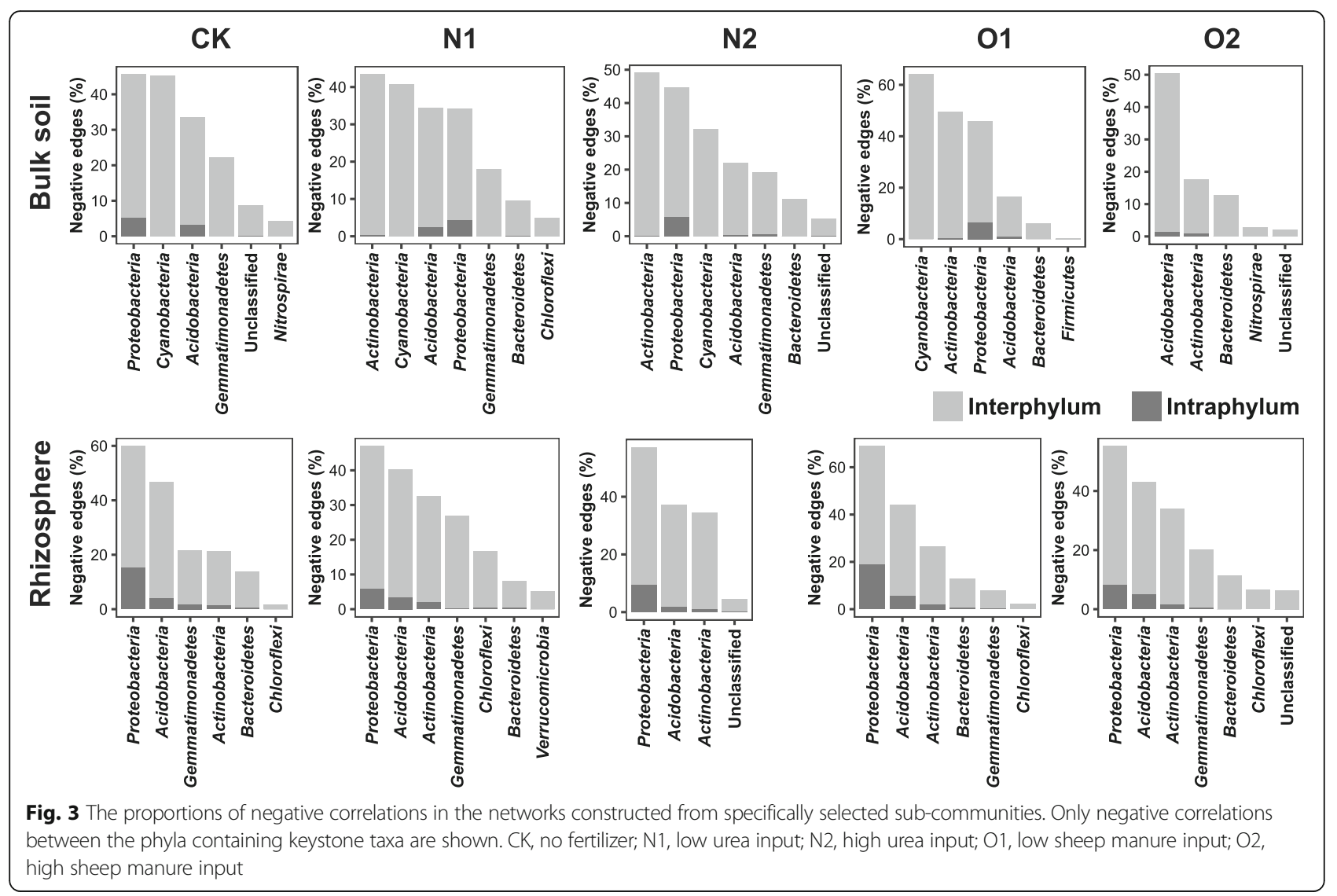

Inter-phylum associations at the overall community level We further verified whether the negative interactions involved with keystone taxa contribute to the correlation patterns of the overall bacterial community. Generally, the pairwise relationships showed that the abundance correlations between Cyanobacteria and the other key phyla were stronger in bulk soils (Fig. 4a) than in rhizosphere (Supplementary Fig. S3a). Specifically, Cyanobacteria had negative correlations with Actinobacteria, Proteobacteria, and Gemmatimonadetes in bulk samples.
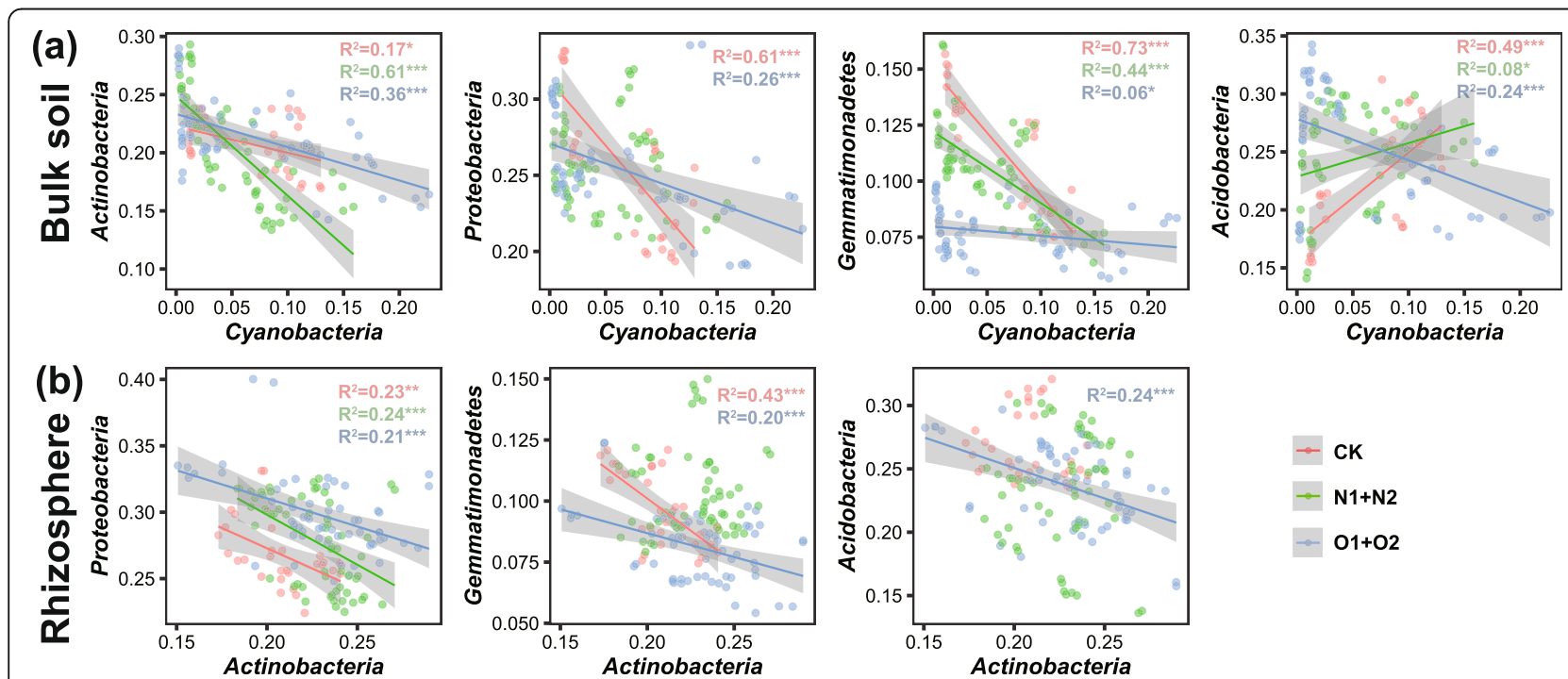

Fig. 4 Pairwise associations between key phyla based on their relative abundances in $\mathbf{a}$ the bulk soil and $\mathbf{b}$ rhizosphere at the community level. Trend lines and goodness-of-fit indexes are added when relationships between variables are significant in linear models. ${ }^{*} P<0.05 ;{ }^{* *} P<0.01 ;{ }^{* * *} P<0.001$ 
However, Cyanobacteria negatively and positively correlated with Acidobacteria under organic and inorganic treatments, respectively, in bulk samples (Fig. 4a).

In addition to the stronger correlations in bulk samples, there were also some stronger abundance relationships in rhizosphere samples, and all the pairwise associations related to Actinobacteria showed higher goodness-of-fit indexes in rhizosphere (Fig. 4b) compared to the bulk soil (Supplementary Fig. S3b). Specifically, Actinobacteria strongly and negatively correlated with Proteobacteria and Gemmatimonadetes in almost all treatments across rhizosphere samples. Moreover, the negative linkages between Actinobacteria and Acidobacteria were strong only under organic nitrogen treatments in rhizosphere samples (Fig. 4b). Furthermore, redundancy analysis also demonstrated that Cyanobacteria and Actinobacteria negatively correlated with other key phyla in the bulk soil and rhizosphere, respectively (Supplementary Fig. S4).

\section{Contribution of functional groups to nitrogen cycling} Cyanobacteria greatly affected the abundances of nitrogen functional genes under the organic nitrogen treatments in the bulk soil based on redundancy analysis (Supplementary Fig. S4). In addition, the 16S rRNA gene of anammox bacteria, as well as nosZ, $A O B$ amoA, nifH, and nirK genes showed positive correlations with Cyanobacteria, and qnorB and nifH genes were positively correlated with Proteobacteria in the bulk soil. While Cyanobacteria were not identified as keystone taxa in rhizosphere, they partly influenced the abundances of nitrogen functional genes in rhizospheric CK treatments. However, Actinobacteria greatly influenced the abundances of nitrogen functional genes together with Proteobacteria in rhizospheric organic treatments. Actinobacteria positively correlated with $A O B$ amoA and $n x r A$ genes, and Proteobacteria positively affected nos $Z$ and $h z s B$ genes in rhizosphere (Supplementary Fig. S4).

The temporally specifically-selected OTUs that significantly predicted variations in the abundance of functional genes constituted functional groups. Proteobacteria, Actinobacteria, Acidobacteria, Gemmatimonadetes, and Cyanobacteria dominated the functional groups, except that Cyanobacteria only accounted for a small part of functional phyla in the rhizosphere (Fig. 5a). Some taxa within the phylum Cyanobacteria primarily contributed to variations in the abundance of the genes involved in multiple nitrogencycling processes, which was revealed by the highest IncMSE values (Fig. 5b).

Figure $5 \mathrm{c}$ showed that there was opposite selection specificity between functional groups at specific stages. For example, Cyanobacteria were inhibited at S1 and S2, and enriched at S4 and S5 in bulk samples. In contrast, most Actinobacteria were enriched at S1 and S2 in bulk samples, except for the $\mathrm{O} 2$ treatment. And Actinobacteria were inhibited at S4 and S5 under N1, N2, and O1 treatments in bulk samples (Fig. 5c). In rhizosphere, such opposite selection specificity between Cyanobacteria and Actinobacteria was detected at S2 and S3 under $\mathrm{CK}$ and $\mathrm{O} 1$ treatments, while this trend was not obvious under other treatments. Moreover, Proteobacteria and Gemmatimonadetes tented to be selected in the opposite direction to Cyanobacteria under CK in bulk samples. Cyanobacteria and Acidobacteria were oppositely selected under $\mathrm{N} 2$ and $\mathrm{O} 2$ treatments in bulk soils (Fig. 5c).

\section{Discussion}

\section{Temporal variations of bacterial community shaped by rhizosphere effect}

Root exudates can shape soil microbial communities during plant development (Chen et al. 2019). In this study, although long-term fertilization treatments maximized the differentiation between different systems, the temporal variation in bacterial community structure was more apparent than the variation caused by nitrogen fertilization treatments (Table 1). A recent study found that nitrogen limitation in the maize rhizosphere outweighed the effects of long-term fertilization on microbiome (Schmidt et al. 2019). Compared with maize, soybean was less dependent on soil nitrogen, since soybean nitrogen demand can be partially met $(50-60 \%)$ by biological nitrogen fixation (Ortez et al. 2018). It is widely acknowledged that rhizodeposition is an important source of available carbon for microorganisms in the vicinity of growing roots (Butler et al. 2003). Rootreleased organic carbon, rather than soil organic carbon or soil active carbon, dramatically varied across wheat growth stages, and closely correlated with bacterial communities (Chen et al. 2019). Therefore, we supposed that the rhizosphere carbon flow related to soybean development affected bacterial community structure more considerably than nitrogen management strategies.

Competition for nutrients between two populations tends to result in the elimination of one population, especially when there is a single resource for competition and when there is no direct contact of these populations (Fredrickson and Stephanopoulos 1981). Herein, the more slight temporal variation in rhizospheric bacterial abundance is consistent with previous findings that microbial communities had less dynamic structure and greater ecological stability in rhizosphere than in the bulk soil (Costa et al. 2006; Thebault and Fontaine 2010). Carbon availability is much higher in rhizosphere than in bulk soils (Martin 2016). The rhizosphere can recruit specific bacteria with the ability to use diverse root-derived carbon substrates (Philippot et al. 2013). The continuous resource supply from root exudates 


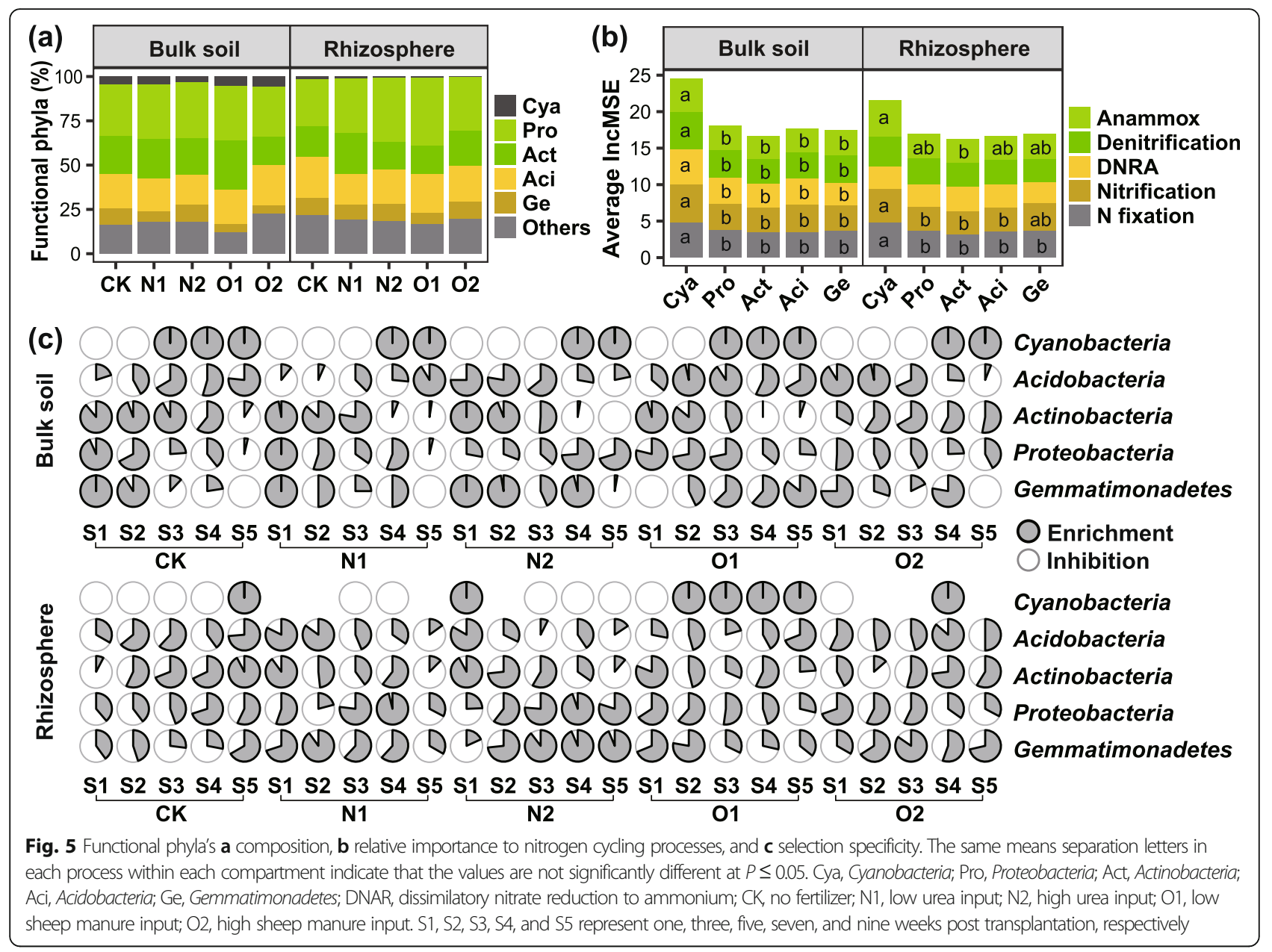

potentially contributed to the reduced variation in the abundance of rhizospheric bacterial communities. Compared with the rhizosphere, the bulk soil obtains relatively limited resources and harbors microbes that are distributed more randomly (Fan et al. 2017). This would intensify bacterial competition for resources in bulk soils, and thereby caused dramatic changes in bacterial abundance.

Previous research has observed temporal shift in carbon utilization by rhizospheric microbial communities with the growth of soybean (Garland 1996). However, bacterial communities showed obvious abundance transitions in bulk soils at the branching stage (S2-S4), with most species enriched at S2 and then inhibited at S4. This can be partly explained by the fact that the rapid growth and nutrient uptake of soybean decrease substrate levels in the surrounding bulk soil at the branching stage (Leggett and Frere 1971; Tanaka et al. 2008), and further change bacterial substrate utilization and competition. Soybean root systems grow fast and display enhanced root exudation at the branching stage (Tanaka et al. 2008). Plant-derived carbon can enter the surrounding soil in the form of low molecular weight organic compounds (Hinsinger et al. 2005). The microbes that can assimilate the plant-derived carbon will be enriched in the bulk soil (Liu et al. 2016b). However, competition between the microbes that share common resources will eventually limit species abundance not to exceed the carrying capacity of the bulk soil, leading to the abundance decline of specific bacteria (Maslov and Sneppen 2017). These results suggested that the rhizosphere effect, especially at the stage of soybean branching, might affect bacterial abundance variation by enhancing bacterial trophic interaction in bulk soils.

\section{Endogenous and exogenous influences on bacterial community dynamics}

A previous study found that the negative links within sub-networks and total networks were much greater in bulk soils than in wheat rhizosphere (Fan et al. 2018). We found a similar trend that the pairwise associations between Cyanobacteria and other phyla were stronger in bulk samples. This could be partly explained by the aforementioned increased competition for limited 
nutrients in bulk soils. However, Proteobacteria, Gemmatimonadetes, and Acidobacteria had stronger negative links with Actinobacteria in rhizosphere than in bulk samples. Given the contribution of Actinobacteria to the promotion of plant growth in rhizosphere (Singh et al. 2018), the interactions mediated by Actinobacteria could provide new insights into the mechanisms of Actinobacteria as bioinoculant for sustainable agriculture.

Cyanobacteria can accumulate extracellular polysaccharides (EPS) which can also be used by other soil microbes (Mager and Thomas 2011). We found that Cyanobacteria engaged in multiple inter-phylum negative interactions in both the specifically selected subcommunities and the overall communities across bulk soils. Compared with the rhizosphere, the bulk soil obtains relatively limited nutrients (Fan et al. 2017). The intensive bacterial competition for EPS in the bulk soil might lead to the negative correlations between Cyanobacteria and other bacteria. Previous studies have observed that nutrient variations oppositely impact the relative abundances of Cyanobacteria and Actinobacteria (Ghai et al. 2014; Ren et al. 2017). This inverse relationship between the members of Cyanobacteria and Proteobacteria was also observed in the coastal water of northern China (He et al. 2017). It has been reported that the occurrence and disappearance of cyanobacterial blooms linked to environmental heterogeneity induces shifts in microbial community composition (Xue et al. 2018). Herein, we found that correlation patterns in the bacterial community were characterized by negative interactions involved with Cyanobacteria in bulk soils.

We noted that Actinobacteria accounted for a larger proportion of negative links than Cyanobacteria in N1 and N2 treatments across bulk soils (Fig. 3), where their keystone taxa negatively and intensively interacted with each other (Fig. 2). This could be explained from two aspects. First, the cyanophycinase produced by Actinobacteria can enable them to directly degrade cyanophycin, which is an important storage polymer of carbon and nitrogen for several Cyanobacteria (Ghai et al. 2013). Second, Actinobacteria are sensitive to organic matterenriched conditions, while Cyanobacteria positively respond to pulsed or sustained nutrient loads (Ghai et al. 2014). Previous studies identified several actinobacterial isolates as nitrate-dependent iron-oxidizers (Kanaparthi et al. 2013). In addition, Actinobacteria can grow efficiently in phosphorus-limited environment (Yao et al. 2016). As such, the increase in nitrate nitrogen and the reduction in available phosphorus concentrations (Supplementary Table S6) could explain the dominance of Actinobacteria under long-term urea addition treatments. Overall, both endogenous interactions and nitrogen management affected the interactive dynamics between Actinobacteria and Cyanobacteria.
Iron is a necessary nutrient for the metabolism of all living organisms (Cruz-Morales et al. 2017). Soybeans are prone to iron deficiency chlorosis, especially in alkaline soils (Rogers et al. 2009). When the Bradyrhizobia that serve as symbionts in soybean are defective in iron uptake and translocation, they elicit ineffective nodules, which do not contain leghemoglobin and lack the ability to fix nitrogen (Benson et al. 2005; Sankari and O'Brian 2016). Iron availability plays important roles in regulating the primary production and nitrogen fixation mediated by Cyanobacteria in marine ecosystems (Krupke et al. 2013). Hydroxamate siderophores (Desferrioxamines) are widely conserved in aquatic and soil-dwelling Actinobacteria, as well as in Gammaproteobacteria and Alphaproteobacteria (Cruz-Morales et al. 2017). Some actinobacterial species were capable of ammonium oxidation coupled to iron reduction (Feammox process) (Huang and Jaffé 2014). Considering the prominent roles of Cyanobacteria, Actinobacteria, and Proteobacteria in interspecies negative interactions, we suggest that the competition for iron via species-specific siderophores may influence bacterial interaction patterns and nitrogen-cycling processes in soybean production systems.

\section{Associations between bacterial communities and nitrogen functional genes}

Previous research reported that microbial communities that were similar in taxonomic composition could have distinct functions, and thereby a subset of microbes might be the key players in mediating biogeochemical cycles (Fan et al. 2021; Zhao et al. 2014). In the present study, we found that bacterial community structure significantly changed over time. However, the abundances of nitrogen functional genes showed some degree of homogenization as the development of soybean. This temporal homogenization was previously reported in the microbial functional profiles of 1-year and 5-year soybean cultivation systems (Mendes et al. 2014). These results reinforced the idea that taxonomically distinct microorganisms could perform similar ecological functions. Apart from microbial functional redundancy, the reservoir role of rare species responding to environmental disturbance could also explain the abundance stability of functional genes (Mo et al. 2018).

As a previous study has highlighted, it is necessary to link the temporal turnover of microbial communities with their functional processes (Liang et al. 2015). Given the dilution effects of less active and inactive species, it is more feasible to explore the associations between community and functional genes by using the temporally specifically-selected sub-community (Yao et al. 2020). Herein, we explored the relative importance of temporally specifically-selected sub- 
communities to functional gene abundance using randomForest. If one species had higher IncMSE value in a certain nitrogen-cycling process, this species might directly perform functions, or indirectly interact with other functional taxa. We noticed that Cyanobacteria strongly predicted multiple nitrogen-cycling processes and actively engaged in inter-phylum negative interactions in bulk soils, which showed that Cyanobacteria tended to affect functional genes in an indirect way by interacting with other functional species.

The influence of microbial communities on microbial functions depends on the function measured (Griffiths et al. 2001). We found that the copy numbers of nifH gene and the associated IncMSE values showed significant negative correlations (Supplementary Fig. S5). For instance, the abundances of nifH gene were significantly lower in CK and N2 than in O1 treatments (Fig. 1c and Supplementary Fig. S6a). Meanwhile, they were predicted better by functional groups under CK and N2 than under $\mathrm{O} 1$ treatments. These results suggested that the abundance decline of nitrogen-fixing functional groups tended to decrease nifH gene abundances. Microbial abundance decline caused by environmental changes can decrease energy investment in nitrogen fixation and increase competition for nutrients (Camenzind et al. 2018). Both Cyanobacteria and rhizobial Proteobacteria are able to fix nitrogen (Louca et al. 2018; Warshan et al. 2017). Considering the strongly negative correlations between Proteobacteria and Cyanobacteria abundances under CK treatment in the bulk soil, their interplay might adversely affect the abundance of nifH gene. These results indicated that the negative interactions between nitrogen-fixing bacteria tended to be coupled with the reduction of nifH gene abundance. This observation could provide references for the better exploration of the correlation between microbial taxonomy and function.

Our findings demonstrate that Cyanobacteria and Actinobacteria have significant negative associations with other keystone phyla in bulk soils and the soybean rhizosphere, respectively. These results provide suitable targets for the future manipulation of the soybean microbiome. Although endogenous interactions and nitrogen management practices have partly explained the interactive dynamics between Cyanobacteria and Actinobacteria, further studies should focus on their interaction mechanisms and their roles in mediating nitrogen cycling and controlling crop production. Another important finding is that the negative interactions between nitrogen-fixing bacteria tends to adversely affect the abundance of nifH gene. This result provides a new perspective for revealing the linkages between the dynamics and functions of bacterial communities.

\section{Materials and methods}

\section{Soil origin, soybean cultivation, and soil sampling}

The soils used in the cultivation experiment were collected from the agricultural station of the Research Center on Agricultural Development Strategy in the Semiarid area of China $\left(108^{\circ} 04^{\prime} \mathrm{E}, 34^{\circ} 18^{\prime} \mathrm{N}\right)$. This region has a temperate continental monsoon climate, with average annual temperature and precipitation of $13^{\circ} \mathrm{C}$ and 600 $\mathrm{mm}$, respectively. The soil type is classified into Udic Haplustalf according to the USDA system (Soil-SurveyStaff 2010). Since 2002, a long-term fertilization experiment was conducted at this station. Winter wheat (Triticum aestivum) was annually fertilized with straw alone (CK; $4500 \mathrm{~kg} \mathrm{hm}^{-2}$ ) or in combination with $50 \%$ (low) or $100 \%$ (high) of nitrogen addition in the form of urea or sheep manure before sowing. The amounts of fertilizers applied were estimated according to their nitrogen contents to reach $120 \mathrm{~kg} \mathrm{hm}^{-2}$ nitrogen or $240 \mathrm{~kg} \mathrm{hm}^{-2}$ nitrogen applied to soil. The soil under CK treatment and the soils that received low urea (N1), low sheep manure $(\mathrm{O} 1)$, high urea $(\mathrm{N} 2)$, or high sheep manure $(\mathrm{O} 2)$ were collected at the depth of $0-15 \mathrm{~cm}$ after harvest on July 16, 2018. Then the soils under the five different treatments were separately mixed and sieved through 2 $\mathrm{mm}$ meshes, and were used for soil property determination and the rhizobox experiment.

The soils used for physicochemical property analysis were transported in ice and stored at $4{ }^{\circ} \mathrm{C}$. Soil pH was determined by a glass electrode with a dry soil to water ratio of 1:2.5. Air-dried soils were sieved through 1-mm meshes before measuring the concentrations of total carbon, total nitrogen, soil organic matter (Soman et al. 2017), available nitrogen including nitrate and ammonium nitrogen, available phosphorus, available potassium, and available iron based on published methods (Sun et al. 2015). The soils used for soybean (Glycine $\max , \mathrm{cv}$. Zhonghuang-13) cultivation were air-dried, and then adjusted to $60 \%$ of field capacity before the transplantation of soybean seedlings. Rhizobox (Supplementary Fig. S1) can separate rhizospheric soil from the bulk soil by $30-\mu \mathrm{m}$ nylon net (Ling et al. 2012). Each fertilization treatment contained six replicate rhizoboxes with $400 \mathrm{~g}$ air-dried soil in each rhizobox.

Soybean seeds were surface sterilized with $2 \%$ sodium hypochlorite for $3 \mathrm{~min}$, and then rinsed with sterile water six times before germination in the dark on $1 \%$ agar plates at $28^{\circ} \mathrm{C}$. Two germinated soybeans were transplanted into the central zone of each rhizobox. To maintain soil moisture, all the 30 rhizoboxes were watered every day using equal amounts of tap water, which was the same as the actual irrigation water. Weeds were manually removed from rhizoboxes. The rhizospheric soils and bulk soils in each rhizobox were collected using 1-ml plastic syringes without tips. And 
each soil sample was transferred into a 2-ml centrifuge tube, which was placed on ice. All the soil samples were immediately stored at $-80^{\circ} \mathrm{C}$ before DNA extraction. Soil samples were collected every other week from the first to the ninth week. The five sampling stages correspond to cotyledon (S1), 1st node (S2), 3rd node (S3), nth node (S4), and blooming stage (S5). All the soil samples were immediately stored at $-80^{\circ} \mathrm{C}$ before DNA extraction. In total, 300 soil samples were collected (five fertilization treatments $\times$ two compartments $\times$ five stages $\times$ six replicates).

\section{DNA extraction, sequencing, and processing}

About $0.5 \mathrm{~g}$ soil from each sample was used for the extraction of genomic DNA using the FastDNA SPIN Kit for Soil (MP Biomedicals, Santa Ana, CA). The V3-V4 region of the bacterial $16 \mathrm{~S}$ rRNA gene was targeted for amplification with primers 338F and 806 (Liu et al. 2016a). Amplification and product purification were preformed according to a previous study (Mei et al. 2019). The PCR products were quantified using a Qubit Fluorometer (Invitrogen, Carlsbad, CA, USA), and were equally mixed to construct libraries. The quantity of amplicon libraries was assessed using the Library Quantification Kit for Illumina (Kapa Biosciences, Woburn, MA, USA). High-throughput sequencing of amplicon libraries was performed on the Illumina MiSeq platform (Illumina Inc., San Diego, USA) at the LC-Bio Technology Co., Ltd. (Hangzhou, Zhejiang, China).

Paired-end reads were truncated by cutting off the sample-unique barcode and primer sequences, and then merged using FLASH. Quality filtering was performed according to the default settings in fqtrim v.0.94 (Bokulich et al. 2013). Vsearch v.2.13.4 was used to remove chimeric sequences (Rognes et al. 2016). The sequence counts obtained from each sample ranged from 21,572 to 69,396 with a median of 37,770 . Then the highquality sequences with $\geq 97 \%$ similarity were assigned to 9452 operational taxonomic units (OTUs) using Vsearch. The taxonomic classification of the representative sequences of OTUs was determined based on the Ribosomal Database Project (RDP) classifier (Maidak et al. 2000). OTUs assigned to chloroplasts were discarded to avoid the debatable classification of cyanobacterial taxa.

To detect the shifts in bacterial community abundance, we filtered OTUs to reduce noise as previously described (Evans and Wallenstein 2014). Those OTUs present in over half of the replicates (e.g., four of six) were deemed 'present', while those OTUs absent in over half of the replicates were deemed 'absent'. Undefined OTUs present in three replicates were excluded together with consistently absent OTUs among six replicates under one fertilization treatment in one compartment.
The species that responded consistently to one treatment in six replicates were retained to explore the assembly dynamics of bacterial communities over time. We further searched for the temporally specificallyselected OTUs from these filtered OTUs. The OTUs with the highest and lowest relative abundances at one specific stage were identified as the specifically enriched and inhibited OTUs at this stage, respectively (Wu et al. 2019). In this study, the temporally specifically-selected OTUs were identified from each compartment under each nitrogen treatment. The difference in the number of the specifically-selected OTUs at each stage was analyzed using independent $\mathrm{t}$ test.

\section{Quantitative PCR (qPCR) of nitrogen functional genes}

To analyze variations in the abundance of nitrogen functional genes in response to nitrogen management and soybean development, we performed qPCR with three replicates on a QuantStudio ${ }^{\text {Tw }} 6$ Flex Real-Time PCR System (Life Technologies Corporation, Carlsbad, CA, USA) using the SYBR Green II method. The mixture of genomic DNA obtained from every six replicates was used as the qPCR template. The nitrogen-cycling processes and functional genes analyzed in this study included nitrogen fixation (nifH), nitrification $(A O B$ amoA, $n x r A$, and comammox clade $A$ ), denitrification (napA, nirK, qnorB, and nos $Z$ ), anaerobic ammonium oxidation (anammox; $h z s B$ and 16S rRNA gene of anammox bacteria), and dissimilatory nitrate reduction to ammonium (DNRA; $n r f A$ ). The abundance of total bacteria was assessed by the copy numbers of $16 \mathrm{~S}$ rRNA gene. The qPCR experiment was carried out according to the previous research (Shu et al. 2019). The qPCR primer sequences and reaction conditions were summarized in Supplementary Table S1.

\section{Data analyses}

All the software packages used in this study were conducted in R environment v.4.0.0 (https://www.r-project. org), and the visualization of graphics were accomplished with the ggplot2 package (http://ggplot2. tidyverse.org) unless otherwise indicated. The dissimilarities of bacterial communities and nitrogen functional genes between different treatment groups were tested via the analysis of similarities (ANOSIM) and permutational multivariate analysis of variance (PERMANOVA). The principle coordinate analysis (PCoA) of community structure was based on Bray-Curtis distance metrics. These analyses were performed using the vegan package (https://github.com/vegandevs/vegan).

The gene abundance differences in different groups were tested using kruskal.test with adjusted $P$ value by the Benjamini and Hochberg method. The log-transformed copy number of each functional gene was visualized using the pheatmap package (https:/CRAN.R-project.org/ 
package=pheatmap). pheatmap package was also used to present the temporal shifts in microbial community abundance under different compartments and fertilization treatments.

To explore the ecological interactions of temporally specifically-selected OTUs, we calculated species-species Spearman's rank coefficients $(\rho)$ using the Hmisc package (https://hbiostat.org/R/Hmisc), and the adjusted $P$ value $(q)$ was calculated based on the false discovery rate method using the fdrtool package (http://strimmerlab. org/software/fdrtool). Significantly correlated OTUs $(q<$ $0.05, \rho>0.7)$ were used to construct the networks of specifically selected sub-communities based on the correlations of OTU abundance variations on time scales. The topological properties (average clustering coefficient, average path length, and modularity) of observed and random networks were calculated using the igraph package (Csardi and Nepusz 2006).

We further identified keystone OTUs according to their among- and within-module connectivity using the criteria (c-score $>0.6$ and/or z-score $>2.5$ ) reported in previous studies (Agler et al. 2016; Guimera and Amaral 2005). The sub-networks of keystone taxa were visualized with Gephi (Bastian et al. 2009). To verify whether keystone taxa dominate the interactions among the temporally specifically-selected OTUs, we calculated the proportions of inter- and intra-phylum negative correlations between the phyla containing keystone taxa in the whole networks. Furthermore, we analyzed the correlations of the average relative abundances of key phyla at the overall community level. The goodness-of-fit and statistical significance of linear regression model were measured using the plyr package (Wickham 2011). The relationships between the relative abundances of key phyla and nitrogen-cycling genes were analyzed using redundancy analysis with the vegan package. The copy numbers of genes were transformed to their natural logarithms after adding one.

To explore the linkages between taxonomic and functional changes, we estimated the relative importance of temporally specifically-selected OTUs to nitrogen functional genes using the randomForest package (Liaw and Wiener 2002). The predictive power of the random forest model was statistically tested using the rfUtilities package (Murphy et al. 2010). The OTUs that significantly predicted functional genes were defined as functional groups. The percentage of the functional groups being specifically enriched or inhibited were shown in pie charts using the corrplot package (https://github.com/taiyun/corrplot).

\section{Supplementary Information}

The online version contains supplementary material available at https://doi. org/10.1007/s44154-021-00015-0.

Additional file 1.

\section{Acknowledgements}

The authors would like to acknowledge Prof. Xiaohong Tian and his group for their efforts in field management.

\section{Authors' contributions}

GHW and DTS conceived and designed the study. CFZ and SJ performed the experiment. CFZ drafted the manuscript. All authors analyzed the data and revised the manuscript. The author(s) read and approved the final manuscript.

\section{Funding}

This work was supported by the National Natural Science Foundation of China [41830755, 41701291, and 42077049].

Availability of data and materials

The dataset analyzed during the current study is available at GenBank's Sequence Read Archive under Bioproject accession number PRJNA675200.

\section{Declarations}

Ethics approval and consent to participate

Not applicable.

Consent for publication

Not applicable.

\section{Competing interests}

The authors have no relevant financial or non-financial interests to disclose.

Received: 30 September 2021 Accepted: 14 November 2021

Published online: 26 November 2021

\section{References}

Abrego N, Roslin T, Huotari T, Tack AJM, Lindahl BD, Tikhonov G, Somervuo P, Schmidt NM, Ovaskainen O (2020) Accounting for environmental variation in co-occurrence modelling reveals the importance of positive interactions in root-associated fungal communities. Mol Ecol 29(14):2736-2746. https://doi. org/10.1111/mec.15516

Agler MT, Ruhe J, Kroll S, Morhenn C, Kim ST, Weigel D, Kemen EM (2016) Microbial hub taxa link host and abiotic factors to plant microbiome variation. PLoS Biol 14(1):e1002352. https://doi.org/10.1371/journal.pbio.10023 52

Asiloglu R, Sevilir B, Samuel SO, Aycan M, Akca MO, Suzuki K, Murase J, Turgay OC, Harada N (2021) Effect of protists on rhizobacterial community composition and rice plant growth in a biochar amended soil. Biol Fertil Soils 57(2):293-304. https://doi.org/10.1007/s00374-020-01525-1

Banerjee S, Schlaeppi K, van der Heijden MGA (2018) Keystone taxa as drivers of microbiome structure and functioning. Nat Rev Microbiol 16(9):567-576. https://doi.org/10.1038/s41579-018-0024-1

Bastian M, Heymann S, Jacomy M (2009) Gephi: an open source software for exploring and manipulating networks. ICWSM 8:361-362

Benson HP, Boncompagni E, Guerinot ML (2005) An iron uptake operon required for proper nodule development in the Bradyrhizobium japonicum-soybean symbiosis. Mol Plant Microbe In 18(9):950-959. https://doi.org/10.1094/ MPMI-18-0950

Bokulich NA, Subramanian S, Faith JJ, Gevers D, Gordon Jl, Knight R, Mills DA, Caporaso JG (2013) Quality-filtering vastly improves diversity estimates from Illumina amplicon sequencing. Nat Methods 10(1):57-59. https://doi.org/10.1 038/nmeth.2276

Brown SP, Grillo MA, Podowski JC, Heath KD (2020) Soil origin and plant genotype structure distinct microbiome compartments in the model legume Medicago truncatula. Microbiome 8(1):139. https://doi.org/10.1186/s40168-02 0-00915-9

Butler JL, Williams MA, Bottomley PJ, Myrold DD (2003) Microbial community dynamics associated with rhizosphere carbon flow. Appl Environ Microbiol 69(11):6793-6800. https://doi.org/10.1128/AEM.69.11.6793-6800.2003

Camenzind T, Hattenschwiler S, Treseder KK, Lehmann A, Rillig MC (2018) Nutrient limitation of soil microbial processes in tropical forests. Ecol Monogr 88(1):4-21. https://doi.org/10.1002/ecm.1279

Chen SM, Waghmode TR, Sun RB, Kuramae EE, Hu CS, Liu BB (2019) Rootassociated microbiomes of wheat under the combined effect of plant 
development and nitrogen fertilization. Microbiome 7(1):136. https://doi. org/10.1186/s40168-019-0750-2

Costa R, Gotz M, Mrotzek N, Lottmann J, Berg G, Smalla K (2006) Effects of site and plant species on rhizosphere community structure as revealed by molecular analysis of microbial guilds. FEMS Microbiol Ecol 56(2):236-249. https://doi.org/10.1111/j.1574-6941.2005.00026.x

Cruz-Morales P, Ramos-Aboites HE, Licona-Cassani C, Selem-Mojica N, MejiaPonce PM, Souza-Saldivar V, Barona-Gomez F (2017) Actinobacteria phylogenomics, selective isolation from an iron oligotrophic environment and siderophore functional characterization, unveil new desferrioxamine traits. FEMS Microbiol Ecol 93:fix086

Csardi G, Nepusz T (2006) The igraph software package for complex network research. InterJ 1695:1-9

Evans SE, Wallenstein MD (2014) Climate change alters ecological strategies of soil bacteria. Ecol Lett 17(2):155-164. https://doi.org/10.1111/ele.12206

Fan KK, Cardona C, Li YT, Shi Y, Xiang XJ, Shen CC, Wang HF, Gilbert JA, Chu HY (2017) Rhizosphere-associated bacterial network structure and spatial distribution differ significantly from bulk soil in wheat crop fields. Soil Biol Biochem 113:275-284. https://doi.org/10.1016/j.soilbio.2017.06.020

Fan KK, Delgado-Baquerizo M, Guo XS, Wang DZ, Zhu YG, Chu HY (2021) Biodiversity of key-stone phylotypes determines crop production in a 4decade fertilization experiment. ISME J 15(2):550-561. https://doi.org/10.103 8/s41396-020-00796-8

Fan KK, Weisenhorn P, Gilbert JA, Shi Y, Bai Y, Chu HY (2018) Soil pH correlates with the co-occurrence and assemblage process of diazotrophic communities in rhizosphere and bulk soils of wheat fields. Soil Biol Biochem 121:185-192. https://doi.org/10.1016/j.soilbio.2018.03.017

Faust K, Raes J (2012) Microbial interactions: from networks to models. Nat Rev Microbiol 10(8):538-550. https://doi.org/10.1038/nrmicro2832

Fredrickson A, Stephanopoulos G (1981) Microbial competition. Science 213(4511):972-979. https://doi.org/10.1126/science.7268409

Garland JL (1996) Patterns of potential C source utilization by rhizosphere communities. Soil Biol Biochem 28(2):223-230. https://doi.org/10.1016/0038 0717(95)00113-1

Ghai R, Mizuno CM, Picazo A, Camacho A, Rodriguez-Valera F (2013) Metagenomics uncovers a new group of low GC and ultra-small marine Actinobacteria. Sci Rep-Uk 3(1):2471. https://doi.org/10.1038/srep02471

Ghai R, Mizuno CM, Picazo A, Camacho A, Rodriquez-Valera F (2014) Key roles for freshwater Actinobacteria revealed by deep metagenomic sequencing. Mol Ecol 23(24):6073-6090. https://doi.org/10.1111/mec.12985

Griffiths BS, Ritz K, Wheatley R, Kuan HL, Boag B, Christensen S, Ekelund F, Sorensen SJ, Muller S et al (2001) An examination of the biodiversityecosystem function relationship in arable soil microbial communities. Soil Biol Biochem 33(12-13):1713-1722. https://doi.org/10.1016/S0038-0717(01 )00094-3

Grosskopf T, Soyer OS (2014) Synthetic microbial communities. Curr Opin Microbiol 18:72-77. https://doi.org/10.1016/j.mib.2014.02.002

Guimera R, Amaral LAN (2005) Functional cartography of complex metabolic networks. Nature 433(7028):895-900. https://doi.org/10.1038/nature03288

He Y, Sen B, Zhou S, Xie N, Zhang Y, Zhang J, Wang G (2017) Distinct seasonal patterns of bacterioplankton abundance and dominance of phyla aProteobacteria and Cyanobacteria in Qinhuangdao coastal waters off the Bohai Sea. Front Microbiol 8:1579. https://doi.org/10.3389/fmicb.2017.01579

Herren CM, McMahon KD (2018) Keystone taxa predict compositional change in microbial communities. Environ Microbiol 20(6):2207-2217. https://doi.org/1 $0.1111 / 1462-2920.14257$

Hinsinger P, Gobran GR, Gregory PJ, Wenzel WW (2005) Rhizosphere geometry and heterogeneity arising from root-mediated physical and chemical processes. New Phytol 168(2):293-303. https://doi.org/10.1111/j.1469-8137.2005.01512.x

Huang LN, Kuang JL, Shu WS (2016) Microbial ecology and evolution in the acid mine drainage model system. Trends Microbiol 24(7):581-593. https://doi. org/10.1016/j.tim.2016.03.004

Huang S, Jaffé PR (2014) Identification of an Actinobacteria species capable to oxidize ammonium under iron reducing conditions. Biogeoences Discussions 11:12295-12321

Kanaparthi D, Pommerenke B, Casper P, Dumont MG (2013) Chemolithotrophic nitrate-dependent Fe (II)-oxidizing nature of actinobacterial subdivision lineage TM3. ISME J 7(8):1582-1594. https://doi.org/10.1038/ismej.2013.38

Konopka A, Lindemann S, Fredrickson J (2015) Dynamics in microbial communities: unraveling mechanisms to identify principles. ISME J 9(7):14881495. https://doi.org/10.1038/ismej.2014.251
Krupke A, Musat N, LaRoche J, Mohr W, Fuchs BM, Amann RI, Kuypers MMM, Foster RA (2013) In situ identification and $\mathrm{N}_{2}$ and $C$ fixation rates of uncultivated cyanobacteria populations. Syst Appl Microbiol 36(4):259-271. https://doi.org/10.1016/j.syapm.2013.02.002

Leggett JE, Frere MH (1971) Growth and nutrient uptake by soybean plants in nutrient solutions of graded concentrations. Plant Physiol 48(4):457-460. https://doi.org/10.1104/pp.48.4.457

Li J, Cooper JM, Lin ZA, Li YT, Yang XD, Zhao BQ (2015) Soil microbial community structure and function are significantly affected by long-term organic and mineral fertilization regimes in the North China plain. Appl Soil Ecol 96:75-87. https://doi.org/10.1016/j.apsoil.2015.07.001

Li Y, Wang M, Chen S (2021) Application of $\mathrm{N}_{2}$-fixing Paenibacillus triticisoli BJ-18 changes the compositions and functions of the bacterial, diazotrophic, and fungal microbiomes in the rhizosphere and root/shoot endosphere of wheat under field conditions. Biol Fertil Soils 57(3):347-362

Liang YT, Jiang YJ, Wang F, Wen CQ, Deng Y, Xue K, Qin YJ, Yang YF, Wu LY, Zhou J, Sun B (2015) Long-term soil transplant simulating climate change with latitude significantly alters microbial temporal turnover. ISME J 9(12): 2561-2572. https://doi.org/10.1038/ismej.2015.78

Liaw A, Wiener M (2002) Classification and regression by randomForest. R News 2:18-22

Liebman M, Graef RL, Nettleton D, Cambardella CA (2012) Use of legume green manures as nitrogen sources for corn production. Renew Agric Food Syst 27(3):180-191. https://doi.org/10.1017/S1742170511000299

Ling N, Zhang WW, Tan SY, Huang QW, Shen QR (2012) Effect of the nursery application of bioorganic fertilizer on spatial distribution of fusarium oxysporum f. sp niveum and its antagonistic bacterium in the rhizosphere of watermelon. Appl Soil Ecol 59:13-19. https://doi.org/10.1016/j.apsoil.2012.05.001

Liu JH, Zhang ML, Zhang RY, Zhu WY, Mao SY (2016a) Comparative studies of the composition of bacterial microbiota associated with the ruminal content, ruminal epithelium and in the faeces of lactating dairy cows. Microb Biotechnol 9(2):257-268. https://doi.org/10.1111/1751-7915.12345

Liu JW, Zhu SQ, Liu XY, Yao P, Ge T, Zhang XH (2020) Spatiotemporal dynamics of the archaeal community in coastal sediments: assembly process and cooccurrence relationship. ISME J 14(6):1463-1478. https://doi.org/10.1038/s413 96-020-0621-7

Liu X, Hu GQ, He HB, Liang C, Zhang W, Bai Z, Wu YY, Lin GF, Zhang XD (2016b) Linking microbial immobilization of fertilizer nitrogen to in situ turnover of soil microbial residues in an agro-ecosystem. Agric Ecosyst Environ 229:4047. https://doi.org/10.1016/j.agee.2016.05.019

Louca S, Polz MF, Mazel F, Albright MBN, Huber JA, O'Connor MI, Ackermann M, Hahn AS, Srivastava DS et al (2018) Function and functional redundancy in microbial systems. Nat Ecol Evol 2(6):936-943. https://doi.org/10.1038/s41559018-0519-1

Mager DM, Thomas AD (2011) Extracellular polysaccharides from cyanobacterial soil crusts a review of their role in dryland soil processes. J Arid Environ 75(2): 91-97. https://doi.org/10.1016/j.jaridenv.2010.10.001

Maidak BL, Cole JR, Lilburn TG, Parker CT, Saxman PR, Stredwick JM, Garrity GM, L B, Olsen GJ et al (2000) The RDP (ribosomal database project) continues. Nucleic Acids Res 28(1):173-174. https://doi.org/10.1093/nar/28.1.173

Martin FM (2016) Carbohydrate metabolism in ectomycorrhizal Symbiosis. In: Nehls U, Das A, Neb D (eds) Molecular Mycorrhizal Symbiosis. John Wiley \& Sons, Inc., New York, pp 159-177. https://doi.org/10.1002/9781118951446

Maslov S, Sneppen K (2017) Population cycles and species diversity in dynamic kill-the-winner model of microbial ecosystems. Sci Rep-Uk 7(1):39642. https:// doi.org/10.1038/srep39642

Mei X, Liu J, Guo ZW, Li PP, Bi SQ, Wang Y, Yang Y, Shen WT, Wang YH, Xiao Y, Yang X, Zhou B, Liu H, Wu S (2019) Simultaneous p-nitrophenol and nitrogen removal in PNP wastewater treatment: comparison of two integrated membrane-aerated bioreactor systems. J Hazard Mater 363:99108. https://doi.org/10.1016/j.jhazmat.2018.09.072

Mendes LW, Kuramae EE, Navarrete AA, van Veen JA, Tsai SM (2014) Taxonomical and functional microbial community selection in soybean rhizosphere. ISME 8(8):1577-1587. https://doi.org/10.1038/ismej.2014.17

Mo YY, Zhang WJ, Yang J, Lin YS, Yu Z, Lin SJ (2018) Biogeographic patterns of abundant and rare bacterioplankton in three subtropical bays resulting from selective and neutral processes. ISME J 12(9):2198-2210. https://doi.org/10.1 038/s41396-018-0153-6

Murphy MA, Evans JS, Storfer A (2010) Quantifying Bufo boreas connectivity in Yellowstone National Park with landscape genetics. Ecology 91(1):252-261. https://doi.org/10.1890/08-0879.1 
Nazaries L, Singh BP, Sarker JR, Fang YY, Klein M, Singh BK (2021) The response of soil multi-functionality to agricultural management practices can be predicted by key soil abiotic and biotic properties. Agric Ecosyst Environ 307: 107206. https://doi.org/10.1016/j.agee.2020.107206

Nelson MB, Martiny AC, Martiny JBH (2016) Global biogeography of microbial nitrogen-cycling traits in soil. P Natl Acad Sci USA 113(29):8033-8040. https:// doi.org/10.1073/pnas.1601070113

Ortez OA, Salvagiotti F, Enrico JM, Prasad PW, Armstrong P, Ciampitti IA (2018) Exploring nitrogen limitation for historical and modern soybean genotypes. Agron J 110(5):2080-2090. https://doi.org/10.2134/agronj2018.04.0271

Perez-Garcia O, Lear G, Singhal N (2016) Metabolic network modeling of microbial interactions in natural and engineered environmental systems. Front Microbiol 7:673. https://doi.org/10.3389/fmicb.2016.00673

Philippot L, Raaijmakers JM, Lemanceau P, van der Putten WH (2013) Going back to the roots: the microbial ecology of the rhizosphere. Nat Rev Microbiol 11(11):789-799. https://doi.org/10.1038/nrmicro3109

Ren LJ, He D, Chen Z, Jeppesen E, Lauridsen TL, Sondergaard M, Liu ZW, Wu QL (2017) Warming and nutrient enrichment in combination increase stochasticity and beta diversity of bacterioplankton assemblages across freshwater mesocosms. ISME J 11(3):613-625. https://doi.org/10.1038/ismej.2 016.159

Rogers EE, Wu XL, Stacey G, Nguyen HT (2009) Two MATE proteins play a role in iron efficiency in soybean. J Plant Physiol 166(13):1453-1459. https://doi. org/10.1016/j.jplph.2009.02.009

Rognes T, Flouri T, Nichols B, Quince C, Mahe F (2016) VSEARCH: a versatile open source tool for metagenomics. Peerj 4:e2584. https://doi.org/10.7717/peerj.2584

Sankari S, O'Brian MR (2016) The Bradyrhizobium japonicum ferrous Iron transporter FeoAB is required for ferric Iron utilization in free living aerobic cells and for Symbiosis. J Biol Chem 291(30):15653-15662. https://doi.org/1 0.1074/jbc.M116.734129

Schmidt JE, Kent AD, Brisson VL, Gaudin ACM (2019) Agricultural management and plant selection interactively affect rhizosphere microbial community structure and nitrogen cycling. Microbiome 7(1):146. https://doi.org/10.1186/ s40168-019-0756-9

Shu DT, Guo JH, Zhang BG, He YL, Wei GH (2019) rDNA- and rRNA-derived communities present divergent assemblage patterns and functional traits throughout full-scale landfill leachate treatment process trains. Sci Total Environ 646:1069-1079. https://doi.org/10.1016/j.scitotenv.2018.07.388

Singh BP, Gupta VK, Passari AK (2018) Actinobacteria from rhizosphere: molecular diversity, distributions, and potential biotechnological applications. In: Yadav AN, Verma P, Kumar S, Kumar V, Kumar M, Sugitha TCK, Singh BP, Saxena AK, Dhaliwal HS (eds) New and future developments in microbial biotechnology and bioengineering. Elsevier B. V, Amsterdam, pp 13-41

Soil-Survey-Staff (2010) Keys to Soil Taxonomy. USDA-Natural Resources Conservation Service, Washington, DC

Soman C, Li D, Wander MM, Kent AD (2017) Long-term fertilizer and croprotation treatments differentially affect soil bacterial community structure. Plant Soil 413(1-2):145-159. https://doi.org/10.1007/s11104-016-3083-y

Strickland MS, Lauber C, Fierer N, Bradford MA (2009) Testing the functional significance of microbial community composition. Ecology 90(2):441-451. https://doi.org/10.1890/08-0296.1

Sugiyama A, Yazaki K (2012) Root exudates of legume plants and their involvement in interactions with soil microbes. Secretions and exudates in biological systems. Springer, pp 27-48. https://doi.org/10.1007/978-3-642-23047-9_2

Sun RB, Zhang XX, Guo XS, Wang DZ, Chu HY (2015) Bacterial diversity in soils subjected to long-term chemical fertilization can be more stably maintained with the addition of livestock manure than wheat straw. Soil Biol Biochem 88:9-18. https://doi.org/10.1016/j.soilbio.2015.05.007

Tanaka N, Kubota F, Arima S, Taguchi M (2008) Quantitative analysis of root system in soybean plant (Glycine max (L.)) (Merrill). JPN J Crop Sci 59(2):270276. https://doi.org/10.1626/jcs.59.270

Tao R, Liang YC, Wakelin SA, Chu GX (2015) Supplementing chemical fertilizer with an organic component increases soil biological function and quality. Appl Soil Ecol 96:42-51. https://doi.org/10.1016/j.apsoil.2015.07.009

Thebault E, Fontaine C (2010) Stability of ecological communities and the architecture of mutualistic and trophic networks. Science 329(5993):853-856. https://doi.org/10.1126/science.1188321

van der Heijden MGA, Bardgett RD, van Straalen NM (2008) The unseen majority: soil microbes as drivers of plant diversity and productivity in terrestrial ecosystems. Ecol Lett 11(3):296-310. https://doi.org/10.1111/j.1461-0248.2007. 01139.x
Warshan D, Espinoza JL, Stuart RK, Richter RA, Kim SY, Shapiro N, Woyke T, Kyrpides NC, Barry K et al (2017) Feathermoss and epiphytic Nostoc cooperate differently: expanding the spectrum of plant-cyanobacteria symbiosis. ISME J 11(12):2821-2833. https://doi.org/10.1038/ismej.2017.134

Wickham H (2011) The split-apply-combine strategy for data analysis. J Stat Softw 40(1):1-29. https://doi.org/10.18637/jss.v040.i01

Wu XJ, Pan J, Li M, Li Y, Bartlam M, Wang YY (2019) Selective enrichment of bacterial pathogens by microplastic biofilm. Water Res 165:114979. https:// doi.org/10.1016/j.watres.2019.114979

Xue YY, Chen HH, Yang JR, Liu M, Huang BQ, Yang J (2018) Distinct patterns and processes of abundant and rare eukaryotic plankton communities following a reservoir cyanobacterial bloom. ISME J 12(9):2263-2277. https://doi.org/10.1 038/s41396-018-0159-0

Yao MY, Elling FJ, Jones C, Nomosatryo S, Long CP, Crowe SA, Antoniewicz MR, Hinrichs KU, Maresca JA (2016) Heterotrophic bacteria from an extremely phosphate-poor lake have conditionally reduced phosphorus demand and utilize diverse sources of phosphorus. Environ Microbiol 18(2):656-667. https://doi.org/10.1111/1462-2920.13063

Yao T, Chen R, Zhang J, Feng Y, Huang M, Lin X (2020) Divergent patterns of microbial community composition shift under two fertilization regimes revealed by responding species. Appl Soil Ecol 154:103590. https://doi.org/1 0.1016/j.apsoil.2020.103590

Ye GP, Banerjee S, He JZ, Fan JB, Wang ZH, Wei XY, Hu HW, Zheng Y, Duan CJ, Wan S, Chen J, Lin Y (2021) Manure application increases microbiome complexity in soil aggregate fractions: results of an 18-year field experiment. Agric Ecosyst Environ 307:107249. https://doi.org/10.1016/j.agee.2020.107249

Zengler K, Palsson BO (2012) A road map for the development of community systems (CoSy) biology. Nat Rev Microbiol 10(5):366-372. https://doi.org/10.1 038/nrmicro2763

Zhang X, Wang Z, Jiang C, Xu J-R (2021) Regulation of biotic interactions and responses to abiotic stresses by MAP kinase pathways in plant pathogenic fungi. Stress Biol 1(1):5. https://doi.org/10.1007/s44154-021-00004-3

Zhao MX, Xue K, Wang F, Liu SS, Bai SJ, Sun B, Zhou JZ, Yang YF (2014) Microbial mediation of biogeochemical cycles revealed by simulation of global changes with soil transplant and cropping. ISME J 8(10):2045-2055. https:// doi.org/10.1038/ismej.2014.46

Zhao YN, Mao XX, Zhang MS, Yang W, Di HJ, Ma L, Liu WJ, Li BW (2021) The application of bacillus Megaterium alters soil microbial community composition, bioavailability of soil phosphorus and potassium, and cucumber growth in the plastic shed system of North China. Agric Ecosyst Environ 307:107236. https://doi.org/10.1016/j.agee.2020.107236

Zhong WH, Gu T, Wang W, Zhang B, Lin XG, Huang QR, Shen WS (2010) The effects of mineral fertilizer and organic manure on soil microbial community and diversity. Plant Soil 326(1-2):511-522. https://doi.org/10.1007/s11104-0099988-y

Zhong YQW, Liu J, Jia XY, Shangguan ZP, Wang RW, Yan WM (2020) Microbial community assembly and metabolic function during wheat straw decomposition under different nitrogen fertilization treatments. Biol Fertil Soils 56(5):697-710. https://doi.org/10.1007/s00374-020-01438-z

\section{Publisher's Note}

Springer Nature remains neutral with regard to jurisdictional claims in published maps and institutional affiliations. 